\title{
29
}

\section{Conversation Analysis and Sociopragmatics}

\author{
Rebecca Clift and Michael Haugh
}

\subsection{Introduction}

In this chapter, we consider what methods and research in Conversation Analysis (CA) can bring to sociopragmatics. In focusing on the co-ordination of action and how particular interactional practices - both linguistic and embodied - implement actions, CA attempts to uncover the generic, context-free procedural infrastructure of interaction (Schegloff 2000) through close, case-by-case analysis of collections of recordings of naturally occurring, spontaneous interaction. With its origins in sociology (Sacks 1992a, 1992b) and its focus on the organization of social life, it does not accord language any principled primacy in the investigation of interaction. However, its methods have done more than any other to identify the means by which language is used in interaction. A central working principle in this respect has been the insistence that both 'position and composition' are equally constitutive in the understanding of action (Schegloff 1993: 121). That is, while linguistic theory has focused overwhelmingly on the compositional elements of language (Clift 2005) - that is, the linguistic features of an utterance - CA gives equal analytic attention to the fact that the utterance has been produced after some specific other utterance in a particular interactional sequence; thus "the construction of talk designed to conduct a certain action is responsive to and bound up with the sequence in which the action is being done" (Drew 2018a: 66). In short, we cannot understand what a particular interactional resource is doing without considering its position within sequences of actions.

Sociopragmatics, in contrast, is located firmly within the analysis of language use. It attempts to uncover the interpersonal and contextual mechanisms driving the use of language by examining a range of different data types, including not only naturally occurring spoken interaction, but also fictional data, written data, and elicited data through a variety of different methods (discourse analytic, corpus-based and experimental 
methods). In essence, it involves person-centred analysis of language use, with a particular focus on meaning and the composition of linguistic units. Research in sociopragmatics thus emphasizes that we cannot understand what a particular linguistic unit is doing without considering who is using it and for what purposes (see Chapter 1).

At first glance CA and sociopragmatics may seem like quite distinct endeavours. They traditionally differ with respect to their main research questions, what counts as data and their method(s) of choice. Our argument in this chapter, however, is that the methods of CA can supply an alternative way into the concerns of sociopragmatics. Evans and Levinson (2009) make the point that "All sciences search for underlying regularities - that's the game, and there is no branch of linguistics ... that is not a player... . The art is to find the highest level generalization that still has empirical "bite"" (475); in giving us analytic traction on interactional data, CA arguably offers compelling empirical 'bite' through its methods. We begin, therefore, by focusing on the two aspects of CA method that make it so distinct from other approaches to language use: transcription and the use of collections. We then go on, in Section 29.3, to illustrate through two case studies how CA work can help us leverage open areas of ongoing interest in sociopragmatics. It is shown that the raison d'être of a CAgrounded approach is that sociopragmatic phenomena should emerge in the course of data analysis, rather than the analyst starting with preexisting categories, such as particular speech acts or identities, and looking for instances of them in the data. We conclude by reflecting on the intersection between CA and sociopragmatics, and possible directions for future research.

\subsection{The Fundamentals of CA Method: Transcription and Collections}

In this section, we discuss two fundamental features of CA methods: the transcription of the data, and the organization of that data into collections of instances of interactional phenomena. We further examine how CA uses collections of instances to furnish both external (exogenous) and internal (endogenous) evidence to bring to bear on the analysis of interaction.

\subsubsection{Transcription}

Perhaps the most visibly distinctive aspect of CA method from all others in the social sciences is the detailed transcription of audio and/or videorecorded data. To those unfamiliar with these transcription conventions, the spelling of what is said, and the symbols - many repurposed from those in standard orthography - capturing how it is said, such details might 
initially appear to be dense and distracting. ${ }^{1}$ However, to understand the rationale for such transcription is to grasp the fundamental basis of the CA approach: that is, that nothing in the data is treated a priori as irrelevant or inconsequential to the building of action in interaction. Sacks' (1984: 22) injunction that we proceed as if there is "order at all points" is pertinent here. The treatment of but one interactional phenomenon - laughter provides us with useful insights into the CA approach to the transcription of data.

Gail Jefferson, tasked by Sacks with transcribing calls from the suicide helpline that furnished the earliest CA data, notes that in standard transcriptions "laughter is named, not quoted" (Jefferson 1985: 28), such as can be seen in line 7 in the transcript she cites below:

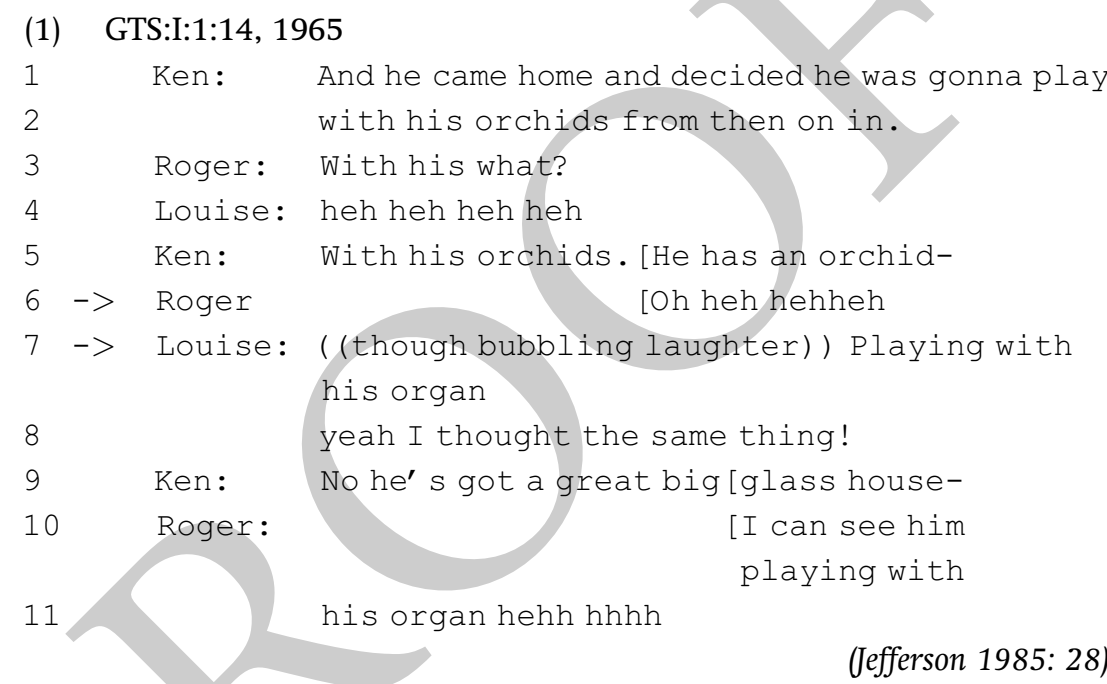

In this transcript, Louise's laughter at line 7 is conveyed much like a stage direction.

In contrast, Jefferson then offers us a re-transcription of the above extract using the conventions she devised for capturing interactional phenomena. The orthography is not standardized, but what Jefferson calls modified standard orthography, designed to look to the eye as it sounds to the ear (Schenkein 1978: xi). Note here at lines 8-9 the transition from what Jefferson calls 'naming' to 'quoting' in her treatment of the laughter:

(2) GTS:I:2:33:R2, 1977

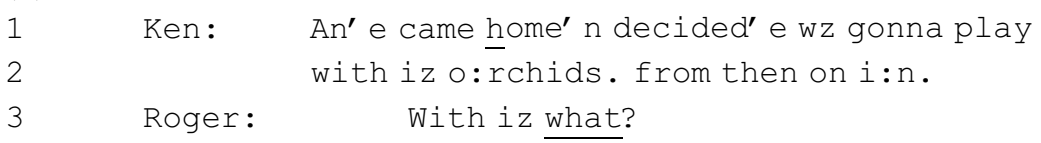

1 We list the key CA transcription conventions we use in this chapter in an appendix. For a more detailed list of these conventions see Jefferson (2004a). For a more extended account of CA transcription see Hepburn and Bolden (2017). 


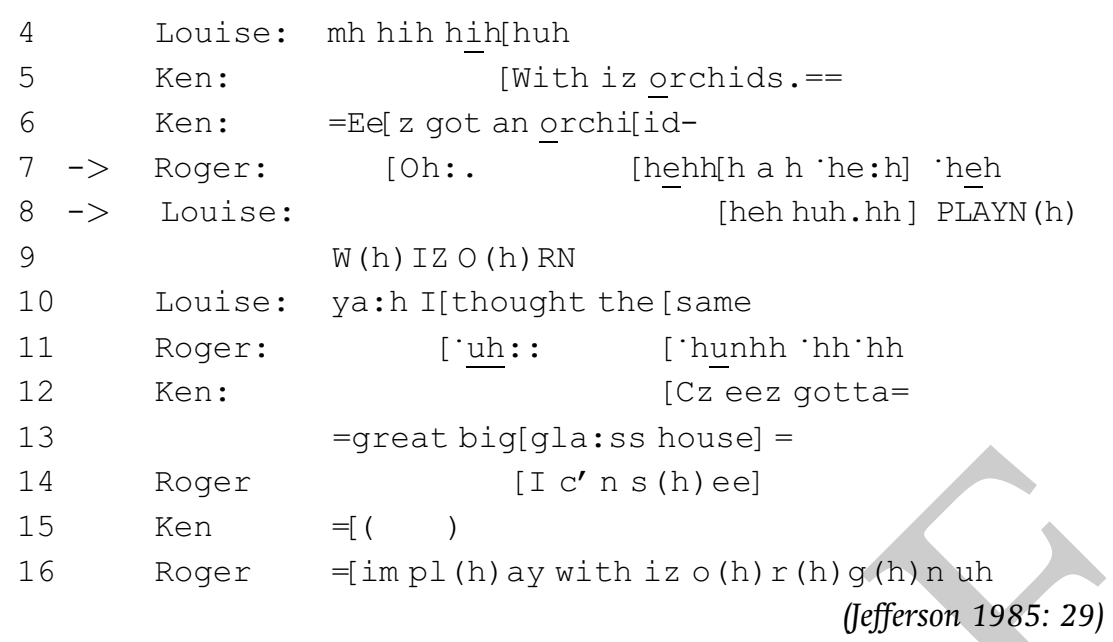

In now quoting, rather than naming, the laughter - that is, representing how it is produced rather than simply registering that it is produced the transcript makes available (to us as analysts) the relationship of the laughter to the utterance. This second transcript captures the production of the laughter in only discrete portions of the utterance: that is, in the course of producing an obscenity. Jefferson (1985) subsequently reflects that:

It may, then, be no happenstance occurrence that the explicit obscenity is slurred, and accountably slurred with the presence of laughter, and that the complex and delicate proposal about the authorship of the obscenity is produced with utter felicity, free of the laughter which can make an utterance difficult to "hear". (Jefferson 1985: 33)

As Jefferson then shows across a range of exemplars, both the presence and absence of laughter are salient; for the first time, laughter is not treated as an uncontrolled flooding out (Goffman 1961), but rather revealed as a methodical device that obscures delicate components of an utterance, thereby implicating a recipient in its authorship. It is the choice to transcribe in this way that makes Jefferson's analysis possible. And indeed her subsequent work on laughter (Jefferson 1979, 1984, 1985, 2004b; Jefferson et al. 1987), stands as a testament to her design of a transcription system which, in her words, "warrants and rewards more than a naming of (laughter's) occurrence” (Jefferson 1985: 34).

Laughter is one phenomenon among many that may not, at first glance at least, seem like a natural focus of sociopragmatics, except perhaps in the context of studies of conversational humour (see Chapter 20). However, Clift's (2012) study of laugh-infiltrated reported speech illustrates how paying close attention to the occurrence of laughter can have considerable analytical payoffs with respect to identifying the action accomplished by that turn (see Chapter 5), as well as for deepening our understanding of 
stance-taking (see Chapter 6) vis-à-vis speaker identities (see Chapter 15). Our more general point is that without detailed transcription of both linguistic and non-linguistic features, the analyst is left blind to the array of resources that can be deployed by participants in interaction.

\subsubsection{Collections}

Alongside the specific transcription system that makes CA so distinct, an emphasis on collections-based analysis lies at the roots of CA. Collecting numerous instances of a given phenomenon makes it possible for the analyst to identify the generic features of that phenomenon - to show that it is produced in a particular sequential environment. It is the use of collections that allows for technical analysis of the action being pursued rather than interpretation of what the speaker may (or may not) have meant on particular occasions (for more on the distinction between action and linguistic meaning, see Clift 2016: 6-9). In one of his earliest lectures, Sacks (1992a) displays this method in his observation that, in calls to a suicide helpline, callers at the beginning of their calls are often claiming to not be able to hear the call-taker; the following is one such instance of the three he gives:

(3)

1 A: This is Mr. Smith, may I help you.

2 B: I can't hear you.

3 A: This is Mr. Smith.

4 B: Smith.

(Sacks 1992a: 3)

The collection of instances he subsequently builds is evidence that there is potentially a systematic practice being deployed that has nothing to do with the claimed hearing problem. In solving the puzzle of what it is that these callers might be doing, Sacks demonstrates that it is a systematic solution to an interactional fix. It is a solution grounded in the apprehension of sequential position as critical to our understanding of action in interaction: the fact that, standardly, one gives one's name at the beginning of an encounter with an unfamiliar, and, further, that one gives one's name in response to the proffer of a name. But a caller in such a situation may have good reasons for remaining anonymous; so how to do so without being seen to do so? Sacks reasons that the callers claiming not to hear are finding a solution to the problem of "having to avoid giving one's name in response to the proffering of another's while not being seen to avoid doing so" (Clift 2014: 99). If Sacks' reasoning regarding this practice is grounded in an understanding of sequential position, his confidence that it is a systematic practice is grounded in his collection of instances. In this way, building and analysing a collection of cases enables the analyst to identify the context-free procedural infrastructure of interaction (i.e. the practice works in the same way across different contexts by 
different speakers), whilst also being able to account for context-sensitive deployment of the practice in question in particular situated contexts. Practices in CA thus encompass assemblages of compositional and positional features of (embodied) talk that make social actions recognizable and accountable to members across contexts (Garfinkel and Sacks 1970).

In seminal work on social action, Schegloff $(1996,1997)$ argues that these practices should be analysed through building collections so that one can establish not only what are canonical instances, but also boundary cases and deviant cases. Boundary cases refer to cases that look like an instance of the practice in question but turn out not to be canonical, while deviant cases refer to instances where there are particular interactional constraints that involve departures from the canonical pattern. The value of boundary cases is that they enable the analyst to zero in on the canonical compositional and positional features of that practice. The value of deviant cases is that they provide evidence that members do indeed orient to it as a practice. The classic instance of a deviant case is in one of the earliest CA collection-based studies, Schegloff's (1968) study of phone call openings. In this study, 1 deviant instance in 500 of a caller, rather than the recipient of a phone call, speaking first, prompted Schegloff to reconsider the rules of sequencing in conversational openings more generally not just in telephone talk. As Clift and Raymond (2018) note, then, "the particular methodological power of collections is located just as much in what they throw into relief. In a search for 'empirical bite', the biting point for CA is not solely in the empirical skewing that emerges through collections of practices, but also in the deviant case: the exception that proves the rule" (94). So evidence for the existence of particular practices may be furnished by means of comparing instances within a collection. But the value of collections goes beyond the comparison of cases to encompass sequence-internal evidence from the data themselves.

\subsubsection{External versus Internal Evidence in Collections}

Two CA studies of requests in social interaction show the value of this bottom-up, data-driven method to the top-down concerns of sociopragmatics. Curl and Drew's (2008) study of the differential deployment of different formats for making requests - although not designed specifically as such - speaks to a central concern of sociopragmatics: politeness. Brown and Levinson's (1987) theory of politeness claims that, in contrast to direct requests, indirect requests reduce the potential threat to the recipient's negative face in making that request (Brown and Levinson 1987; cf. Chapter 16). Curl and Drew's (2008) focus is not 'indirect' versus 'direct' requests as such, or at least, it is not stated in such terms, but rather two distinct formats that were identified in their data: those requests prefaced by "would/could you" and those prefaced by "I wonder if". A key finding that emerges from their analysis was that these "different formats were 
used by speakers to display or claim entitlement to make a request and to display (or conversely, not acknowledge) an understanding of the contingencies associated with granting their requests" (Curl and Drew 2008: 139, emphasis added). In short, speakers implicitly claim a higher entitlement to make the request in question and that the contingencies of granting that request are low through the use of modal verbs (e.g. can/could I ...), while speakers index a lower entitlement to make the request and that there are greater contingencies associated with granting that request through the use of more contingent forms (e.g. I wonder if ...). The fact that these regularities hold across the two datasets investigated by Curl and Drew - one of phone calls amongst friends and family, the other a corpus of after-hours calls to family doctors - suggest that these orientations are generic and irrespective of individual differences. ${ }^{2}$

Curl and Drew's (2008) work on requests is a paradigmatic study of how exogenous evidence from language use can be gathered from collections revealing participant orientations. Such empirical skewing towards a particular format in a specific context is made possible by the existence of the parallel cases that constitute a collection. But the data can also itself supply endogenous evidence of participant orientations. In subsequent work on requests, Drew et al. (2013) use evidence from an analysis of a collection of self-repairs - where speakers work to address 'problems in speaking, hearing and understanding' (Schegloff et al. 1977: 361) - to illustrate how participants may orient to changing contingencies in selecting different formats for making those requests. In the following excerpt, Leslie is negotiating with her daughter Kath, who lives away at college, as to when Kath will return home for Christmas.

(4) Field $\mathrm{X}(\mathrm{C}) 85: 2: 1: 4$

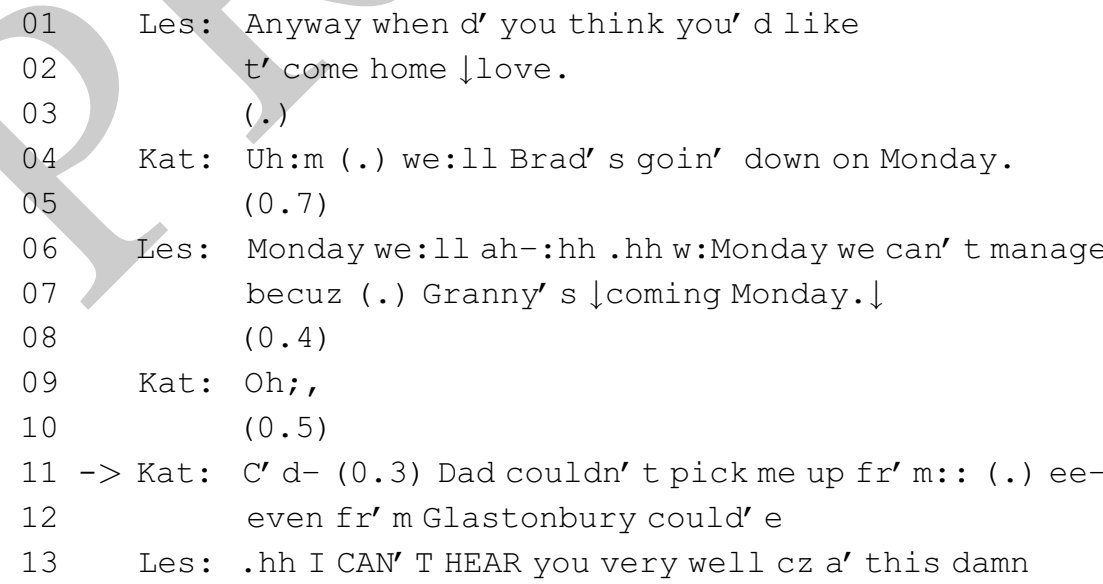

\footnotetext{
2 As we discuss in the following section, this context-free procedural infrastructure can then be used to empirically ground a sociopragmatic analysis of "embodied actors, bringing the elements of the organization of human sociality just mentioned into being moment by moment in a particular place, with particular others, vying with or yielding to one another, etc" (Schegloff 2010: 38).
} 


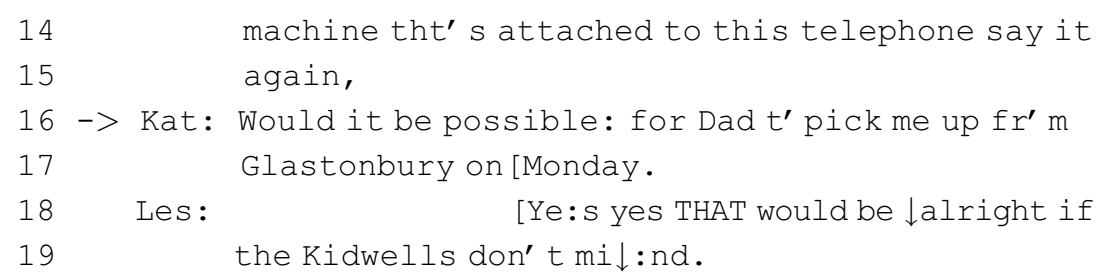

(Drew et al. 2013: 89-90)

In response to her mother's response that they can't pick up Kath on Monday (lines 6-7), Kath begins her request, in line 11, with a modal (i.e. "C'd"), but she then aborts this and replaces it with what is initially a negative declarative statement that is transformed ultimately into a negative interrogative by dint of the tag question ("Dad couldn't ... could'e”). In so doing, Kath "more firmly orients to the difficulty that has arisen (that her father may not be able to collect her), and hence to the changed contingencies" (Drew et al. 2013: 90). Following a claim from her mother that she is unable to hear her properly (lines 13-15), Kath uses a more contingent form ("would it be possible") that orients to the compromise that her father pick her up from somewhere closer rather than driving all the way to her college (lines 16-17). This elicits conditional granting, in turn, from her mother (lines 18-19). The take-home point here is that there is data-internal evidence, through self-repair, of a speaker's orientation to a range of contingencies.

Thus we have both exogenous and endogenous evidence, through collections-based analysis, of a speaker's orientation to different contexts in her selection of specific formats. While not initially designed to interrogate the claims in Brown and Levinson (1987), the work in both Curl and Drew (2008) and Drew et al. (2013) serves to illuminate the claims made by politeness theory by reference to the data of actual language usage.

Having discussed two central features of CA method - transcription and collections - we now turn in the following section to pursue further the means by which CA has been able to lever open sociopragmatic concerns. We illustrate this through case studies focusing on two key topics in sociopragmatics: (1) speech acts and indirectness, and (2) inference and identity.

\subsection{CA-Grounded Sociopragmatics}

In CA-grounded sociopragmatics, the aim is for the analyst to pay close attention to the details of actual talk - through transcription - in order to identify recurrent patterns in the production of that talk - through collections. This approach is the classic 'bottom-up' approach to data which allows sociopragmatic phenomena to emerge in the course of data analysis, rather than, as with 'top-down' approaches, starting with pre-existing 
categories and searching for examples of them in data. ${ }^{3}$ CA methods thus encourage us to go beyond the study of vernacularly named phenomena, while the procedural account of social action in CA offers a tertium comparationis or "common platform of reference" (Krzeszowski 1990: 15; cf. Chapters 10 and 31) across languages and cultures. A procedural account of social action is grounded in the analysis of the recurrent practices by which actions are interactionally accomplished. In identifying context-free, and thus potentially universal dimensions of this procedural infrastructure, CA thereby provides an empirical basis for comparative work across languages. ${ }^{4}$

CA-grounded approaches have been implemented in the study of a range of different sociopragmatic phenomena, including 'face' (e.g. Arundale 2010, 2020; Merrison 2011), 'politeness' (e.g. Cook 2006; Ferenčik 2007; Haugh 2013), 'impoliteness' (e.g. Bayraktaroğlu and Sifianou 2012; Hutchby 2008; Piirainen-Marsh 2005) and 'relationships' (e.g. Pomerantz and Mandelbaum 2005; Flint et al. 2019). In what follows we illustrate what methods in CA can offer through two case studies that touch upon selected areas of ongoing interest in sociopragmatics: indirectness and identities. We begin by considering how a CA-informed approach to action can recast our understanding of the kind of action categories familiar to us from Speech Act Theory (Austin [1962] 1975; Searle 1969; see also Chapter 5), and the implications of this for the study of what has traditionally come under the rubric of 'indirectness'. This motivates our subsequent discussion of the role played by identities in attributing inferences to talk.

\subsubsection{Case Study 1: Social Action and Indirectness}

Our first case study shows what is entailed in a CA-grounded approach to sociopragmatics by examining the following data extract. This piece of data has been selected because through it we can see very clearly how actions and indirectness are conceptualized in Speech Act Theory-based approaches to language use, and how CA methods can further illuminate the nature of the actions being prosecuted across the sequence. The excerpt comes from a longer exchange between Mike with his old music teacher Mary at her home. Prior to this excerpt, Mary, who is not particularly mobile, has prepared tea for them both, and they have both just sat down to start eating some biscuits:

\footnotetext{
3 An important point of departure for our overview of CA-grounded sociopragmatics is the repeated cautioning in CA about the problems that can arise when we use vernacular categories in analysis. These include folk terms for actions in talk (e.g. requests, apologies etc.) and various kinds of identities (e.g. cultural, gender etc.). Schegloff (2017: 437), for instance, argues that we should not rely on such categories, except and insofar as they are invoked by the participants themselves as we attempt to start to make sense of our data. This is not to say, however, that systematic studies of how people talk about language use and its bearing on evaluations of it are not useful (see Chapter 7).

${ }^{4}$ For studies that illustrate recurrent aspects of the sequential organization of social action across a diverse range of languages, for instance, see Floyd et al. (in press) and Kendrick et al. (in press).
} 


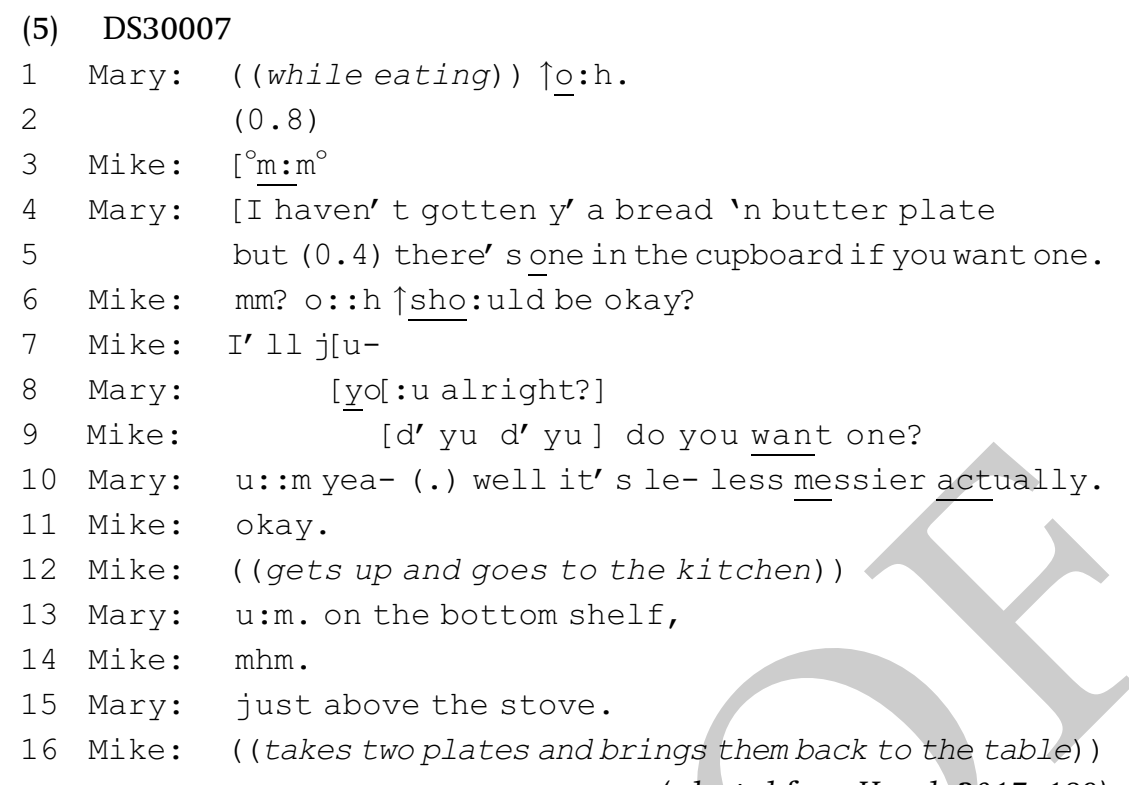

(adapted from Haugh 2017: 189)

The outcome of the above exchange is that Mike and Mary end up with plates from which to eat their biscuits. But how is this course of action achieved? A broad gloss of what is apparent in the above exchange might be that, in the course of 16 lines, Mary indirectly offers Mike a plate (line 5) by informing him as to where he can find one (as opposed to a direct offer, e.g. of the form 'would you like a plate?'), and Mike declines the offer (line 6), subsequently producing an indirect counter-offer to get a plate for her (line 9). Mary indirectly accepts the offer (line 10), whereupon Mike, under Mary's direction, finds the plates for them to use (line 16). It might be further proposed, under a pragmatic analysis, that Mary's initial indirect offer - 'there's [a bread and butter plate] in the cupboard if you want one' is subsequently revealed to be a 'hint'. Approaches grounded in the analysis of speech acts, such as Brown and Levinson's (1987) politeness theory would call such a strategy an 'off-record indirect request' for a plate - a strategy oriented to the addressee's 'negative face' and desire to preserve his autonomy in a way that, for example, 'Could you get us some plates?' would not. Such an account initially seems plausible to capture what we see in the exchange.

However, such an account only serves, in Schegloff's (2007) words, to "invoke and parlay 'the reader's experience' without having to offer a definition, explanation, or evidence” (88); 'offers' and 'requests' are familiar enough categories in both lay and Speech Act Theory terms, and the notions of 'direct' and 'indirect' utterances are derived from a purely compositional approach to the study of language, where the sole focus is trying to establish what an utterance might be doing with reference to its form. Such a 'top-down' gloss makes no reference, however, to the orientations of the 
participants themselves in deriving the categories of action. In contrast, CA's 'bottom-up' approach puts participants' own displayed understandings as shown in 'next turn' at the centre of the analysis. In so doing, it moves beyond a speech act focus on the individual utterance or utterance pair to focus on the wider interactional sequence in which the actions are embedded; it recognizes that utterances are not unilateral but necessarily implemented across sequences. Drew and Holt (1998) capture this focus in their observation that

the components of a turn's construction - at whatever level of linguistic production - are connected with the activity which the turn is being designed to perform in the unfolding interactional sequence of which it is a part, and to the further development of which it contributes. (497)

The immediate upshot of focusing on the wider sequence of action in which any given turn is embedded is thus to see that, to take but one example, Mike's offer to get a plate at line 9 cannot but be seen in the context of his immediately prior declination of Mary's offer, and, as he moves to expand on and account for that declination (with what is projectably about to be something like 'I'll just do without'), Mary's line 8 , in which she pursues the matter, having received a declination of her offer ('should be okay?', line 6), effectively disattends that declination. Note also the contrastive stress on 'want' in Mike's offer: 'do you want one', which topicalizes Mary's wishes, in contrast to Mary's prior topicalization of Mike's wishes in her original offer (line 5). A speech act analysis essentially shows us that this sequence contains two offers: Mary's (lines 4-5), which is declined, and Mike's (lines 9-10), which is accepted. But it cannot tell us the relationship between these offers, and the visible evidence that comes from the positioning of Mike's offer as it intersects with Mary's pursuit at line 8, that it is motivated by Mary's initial offer. In trying to understand actions in interaction we can, however, bring to bear on this extract evidence from collections-based CA work to show that there are specific practices in interaction that implement particular practices. In this respect, work by Kendrick and Drew (2016) on what they call 'recruitments' is directly pertinent to this exchange. Recruitments constitute a category of practices by which participants enlist assistance from others. Requests form one such subset; as the work of Curl and Drew (2008) shows, these involve a range of different request formats that are responsive to different interactional entitlements and contingencies; enlisting assistance through reporting troubles, difficulties, needs or noticeable absences is another type of recruitment practice (Kendrick and Drew 2014). In this light, it is possible to hear Mary's 'I haven't gotten y'a bread 'n butter plate' (line 4), as clearly formulating an absence; and, in her pursuit of the matter even in the face of Mike's refusal, and in her ultimate assent to his offer in line 10, we can see evidence that the exchange above constitutes a recruitment sequence. In 
this respect, we can see that, by examining actions in their unfolding production across sequences, we can arrive at the general category of recruitments by working 'bottom-up', in reference to participants' own orientations, achieving empirical 'bite' - and in so doing, discover a hitherto unidentified category of action.

From the very beginning of the sequence, with the noticing that registers, with 'oh', a change-of-state from not-knowing to knowing in line 1 (Heritage 1984), CA also offers us a wealth of analytic leverage to open up what these two participants are doing beyond simply glossing it as an instance of "negative politeness". Let us take but one instance of a turn, line 10, Mary's acceptance of Mike's offer. In examining the moral and interpersonal implications of its occurrence here in this particular situated context, we attempt to further illustrate what detailed transcription and collections-based analysis of social action can bring to our understanding of 'indirectness'.

Mike's offer, in line 9, is delivered through a polar interrogative, that is, using what Curl (2006) terms a DYW (do you want me to ...?) syntactic form, which frames it as responsive to a problem that can be deduced from their prior talk: if Mike does not have a plate (line 4), then neither does Mary. While a speech act-based approach such as Brown and Levinson's (1987) politeness theory might just note that Mary accepts the offer, attention to the detail of the production of the talk, captured in the detail of the transcription, reveals that the acceptance of this offer is accomplished in anything but a straightforward manner. We note, for instance, the stretched ' $\mathrm{U}:: \mathrm{m}$ ' that constitutes the immediate response; the cut-off on Mary's 'yea-' and then the micropause that follows in its wake, before Mary reformulates her turn, prefaced by 'well'. In the first instance, the initial ' $\mathrm{U}:: \mathrm{m}$ ' in response to an offer, as the second part of an adjacency pair (Schegloff 2007) indicates that a dispreferred response is upcoming (Pomerantz 1984) - that is, a response which disaligns with the activity proposed in the first pair part (Schegloff 2007: 59). However, she then starts to produce a type-conforming response (Raymond 2003) - that is, a 'yes' response to a 'yes'-'no' question - but then subsequently initiates a self-repair to delete acceptance of the offer in favour of an account ("well it's less messier actually") (Robinson 2016). The latter is delivered through three key components: well-prefacing, the account itself and turn-final actually. Drawing on CA studies of collections of each of these components, it becomes evident that they are delicately shaping the benefactive stance Mary is enacting in the course of accepting Mike's offer (Clayman and Heritage 2014). For example, a study of well-prefaced responses to 'yes''no' questions by Schegloff and Lerner (2009), argues that turn-initial "well" is used in response to questions to indicate that the following answer will be non-straightforward, while accounts are canonically associated with dispreferred turn formats (Pomerantz and Heritage 2013). In this case, the account proposes the grounds for acceptance of this offer 
("it's less messier") as based in a practical, rather than personal, motivation. Finally, a fine-grained analysis of "actually" in different positions within turns by Clift (2001) has found that turn-final "actually" is associated with responses that are counter to the attributed expectations of the recipient. So, through this highly granular turn design (Schegloff 2000), Mary construes herself not as the beneficiary of an offer that addresses a 'desire' to eat with a plate, but rather the beneficiary of an offer that addresses the 'trouble' that can be engendered by eating without a plate a 'trouble' that applies as equally to Mike as it does to Mary. This nonstraightforward response thus enacts a stance in which both her and Mike are beneficiaries, substituting for the one previously enacted by Mike in which she was the sole beneficiary of the plate-getting. In responding in this way, Mary also neatly avoids being held accountable for the agenda that Mike appears to be attributing to her prior inquiry in line 8 through his DYW-formatted offer in line 9 (Pomerantz 2017). In the course of this sequence, then, Mary recruits assistance from Mike, that is, he gets plates for them both, but accepts this assistance in such a way that leaves it equivocal as to whether that was her design all along. This has important moral implications, as Mike is positioned as volunteering, rather than being requested to offer, assistance (Haugh 2017).

A collection-based analysis of responses to prompted offers of the type identified above found, in English at least, that they were "recurrently granular, designed in ways that avoided straightforward acceptance of the offer of assistance" (Haugh 2017: 196). This reflects, in turn, an orientation to a complex set of entitlements and contingencies (Curl and Drew 2008), which the practice of prompting offers appears designed to address. We take these issues up in the next section - but register for now that examining the very different ways in which Mary and Mike choose to package their offers has revealed the means by which participants make choices from the interactional resources available to them. In Mary's choice to report an absence that establishes the relevance of a solution, that is, an offer of assistance (Kendrick and Drew 2014), and her acceptance of Mike's offer with a dispreferred turn format, we see the means by which participants conduct collaborative courses of action while remaining alert to the contingencies of their particular situation.

In sum, a CA perspective highlights the sequential practices by which participants make available and contest the ascription of actions - in the case above, the type of "offer" is Mary accepting here and the terms on which she is accepting that "offer" - and the interpersonal and moral implications of construing actions in just those ways (Haugh 2015, 2017, forthcoming). In short, what CA offers is an empirically grounded way of linking the accomplishment of action with what comes under the broader rubric of politeness in sociopragmatics. It thus offers a method of advancing Brown and Levinson's (1987) original insight that politeness is tied to the composition of particular speech acts (e.g. "bald-on-record imperatives" 
versus "off-record indirect requests") in a way that addresses the subsequent shift in sociopragmatics towards examining politeness in naturally occurring interaction rather than at the utterance level. What CA adds to this discursive turn in sociopragmatics is the insight that paying close attention to the position of utterances, in addition to their composition, is important. One way of doing so is through detailed transcription and collections-based analysis of the various practices by which actions are interactionally achieved.

\subsubsection{Case Study 2: Inference and Identity}

In the previous section we pointed to a complex set of entitlements and contingencies that may shape the actions being implemented across sequences. We noted in passing that Mary has prepared tea for Mike at her home, but did not otherwise invoke aspects of identity in the analysis of the exchange. However, participant orientations to one or another aspect of their identities is surely displayed in their positioning of themselves with respect to each other in talk; note, for example, that it is Mary who registers the absence of a plate, rather than Mike. But how do we systematically ground orientations to identity in talk? In what follows, we elaborate on these by reference to work in CA on identities in interaction, and the link between identity and a central feature of work in sociopragmatics: inference.

The link between identities and inference has long been noted in work on what Harvey Sacks termed membership categorization (Sacks 1972). ${ }^{5}$ In a famous observation, Sacks notes that anyone hearing 'The $\mathrm{X}$ cried. The Y picked it up' - taken from a story told by a two-year-old (1992a: 243-51) could immediately grasp that ' $\mathrm{X}$ ' would be the category 'baby' and ' $\mathrm{Y}$ ' would be 'mummy' (rather than, say, 'dentist' and 'footballer', to take two random examples). Moreover, the 'mummy' is understood to be the 'mummy' of the 'baby', and picking up the baby is understood to be a consequence of the baby crying. ${ }^{6}$ Such categories are thus inference-rich, a point also well noted by Levinson (2000) in his discussion of generalized conversational implicatures (see Chapter 3).

Consider, for example, how the referent of a pronoun is derived by inference in the following exchange, through familiarity with British social norms regarding husband-and-wife couples. Lesley's 'We have friends in Bristol' (line 3) allows her to refer subsequently to 'he' (lines 7 and 13) as one member of the invoked couple, the husband:

\footnotetext{
${ }^{5}$ See Clift (2016: 186-95) for an overview of how identity has been studied through the lens of the membership categorization device in CA.

${ }^{6}$ We note that ' $Y$ ' might now potentially include 'daddy' reflecting the ways in which inferences from categories can be shaped by changing social norms.
} 
(6) Holt 2:3

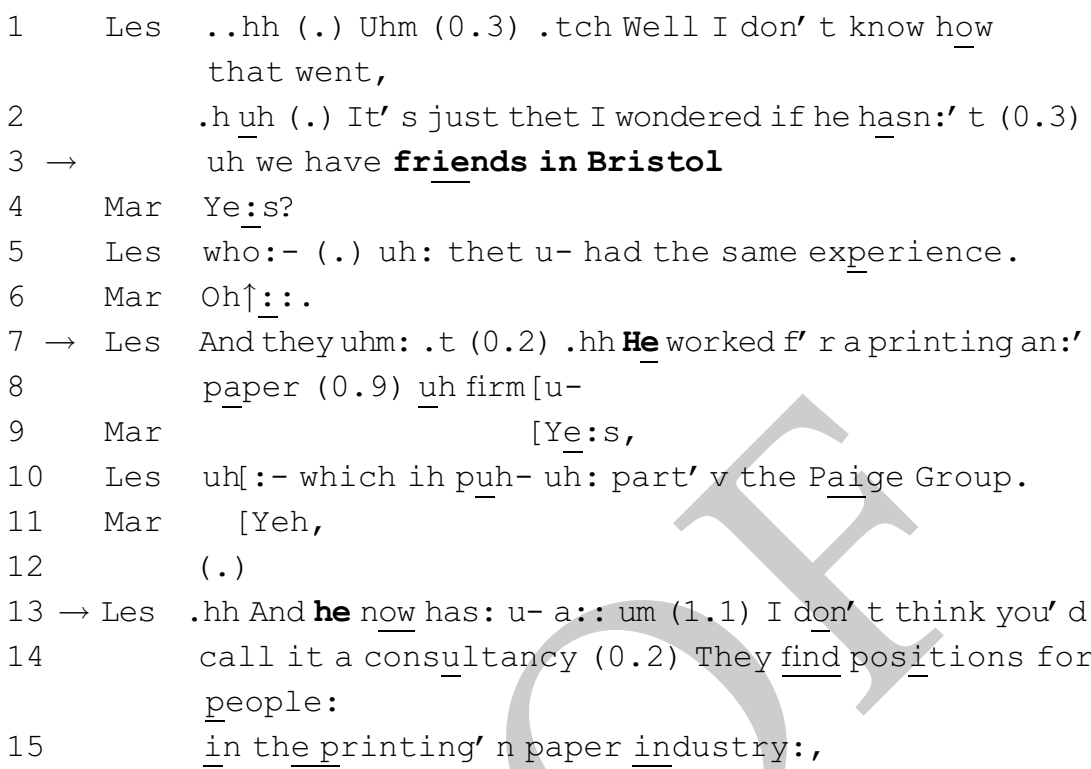

(Kitzinger 2005: 249)

'He', then, is derived by pragmatic inference; and, as the sequence shows, the recipient displays no trouble in accessing the referent (as displayed in her 'Yes' in line 9, rather than, say, 'Who?'). We thus have evidence in the data itself of the inference-generating nature of membership categories.

The ways in which orientations to particular category labels can shape sequences of action is further brought out by the work of Kitzinger and Mandelbaum (2013) who investigate how the categories 'expert' as distinct from the 'layperson' are invoked across two sequences of action. Expectable sets of knowledge and competencies are part of the attribution of category membership. In the following extract, the call-taker on a Birth Crisis helpline uses the term 'doulas' (line 4), but adumbrates it with an inbreath and produces it with try-marking, that is, upward intonation (Sacks and Schegloff 1979), and then checks the caller's understanding of the term ('D'you know what doulas are', lines 4-6), thus showing her understanding that she is not talking to someone occupying the identity category 'childbirth expert':

(7) (CT = call-taker on a Birth Crisis helpline, here listing the occupations of the other call-takers servicing the helpline. DAW is the caller)

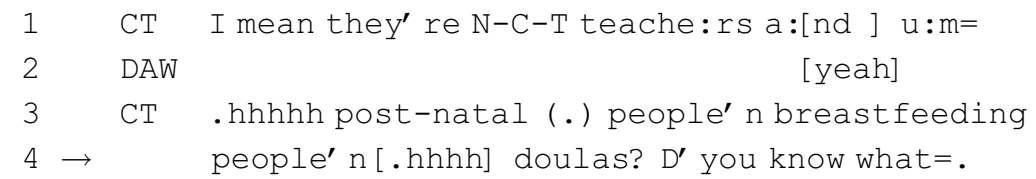




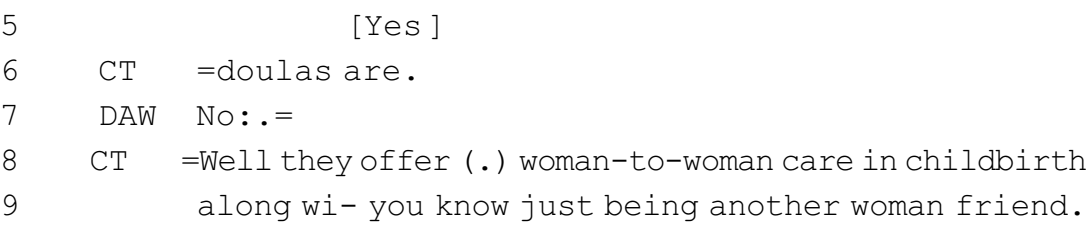

(Kitzinger and Mandelbaum 2013: 6)

The call-taker's decision to check her recipient's familiarity with the term is clearly justified in this case, and the sequence gets further expanded as the call-taker provides an explanation (lines 8-9). Compare this sequence, expanded in its course with question and answer at lines $4-5$, with the following use of the same term, used with no understanding check by the speaker - a confidence endorsed by the recipient:

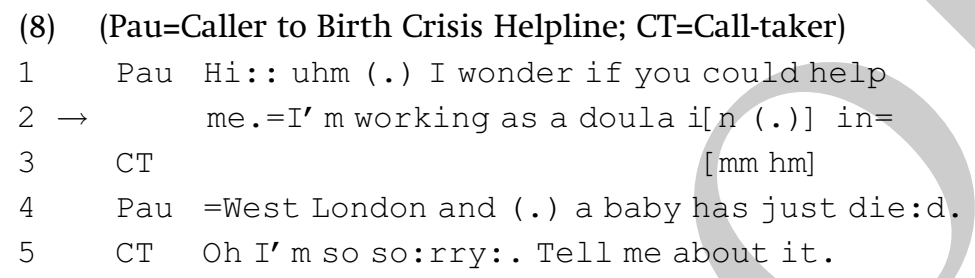

(Kitzinger and Mandelbaum 2013: 7)

Here, the announcement in line 4, 'a baby has just died', gets immediate condolences in the next turn, and the term 'doula' is not treated as problematic by either party, with the call-taker receipting the term with a continuer in line 3. We can thus see that the orientation to one or another category - 'expert' or 'layperson' has a consequential effect on the progression of the sequence. In (7) it is temporarily halted; in (8) it is not. Note, in particular, that nowhere are such categories explicitly named, but rather implicitly invoked through speakers' orientations. Thus, rather than imposing pre-existing categories onto the data, CA shows the relevance and salience of identity categories to participants through the talk itself.

In a ground-breaking study of identity in CA, Raymond and Heritage (2006: 681) note that: "there can be direct links between the identities of participants and the rights and responsibilities associated with those identities that are directly implicated in practices of speaking”. Raymond and Heritage demonstrate these links by reference to their work on epistemic rights in interaction, in which they show how the producers of first and second assessments ${ }^{7}$ in talk can, through particular grammatical practices, index the relative primacy and subordination of their assessments relative to that of co-participants. So, note how in the exchange from a phone call below, Jenny's assessment in line 1 of Vera's son and his family, 'They're a

\footnotetext{
${ }^{7}$ First assessments are those that initiate sequences, while second assessments are responsive to a (just) prior assessment.
} 
lovely family now" is appended, turn-finally, with a tag question, and is met, in line 2, by a confirmation plus an agreement from Vera ("They are, yes"):

(9) Rahman: B:2: JV(14):4



As Heritage and Raymond (2005) make clear, the syntactic form of lines 1 and 2 make specific claims vis-à-vis the rights of their speakers to make their relative assessments. Heritage and Raymond show that the speaker going first with an assessment by default claims primary rights to assess, and the speaker going second, by the same token, claims subordinate rights to make that assessment. But speakers in those positions can upgrade or downgrade those claims by means of particular grammatical resources. In excerpt (9), Jenny's first position assessment ('They're a lovely family now') is downgraded by means of the tag question, which transforms the declarative format into an interrogative in asking her recipient for confirmation; in doing so, Jenny cedes epistemic primacy to Vera. In turn, although Vera is in second position with respect to the assessment, she upgrades her rights to assess by producing a confirmation ('they are'), followed by an agreement ('yes'). As Heritage and Raymond (2005: 23) note, in treating confirming as the priority, a speaker can propose that one held this position prior to, and independently of, her co-participant. What the exchange above thus shows us is a speaker in first position downgrading her rights to assess and a speaker in second position upgrading hers. By negotiating their respective rights to assess the family, these two speakers show the relevance to themselves of particular identity categories. As in examples (7) and (8), nowhere is the relevant category explicitly invoked or referred to, but the relevance of Vera's identity as 'grandparent' is, as Raymond and Heritage (2006) make clear, indexed throughout the conversation.

In this way, then, CA finds, in the details of the talk itself, participants' own orientations to particular category memberships. The role of identities in generating inferences about who knows what, who has more rights to know that and so forth, is empirically grounded in detailed collectionsbased analysis of the practices by which participants make such inferences recognizable and relevant to each other. The notion of epistemic rights may 
be as abstract a concept as politeness, but this 'bottom-up' method of data analysis allows us to achieve 'empirical bite', as part of the highest-level generalization demanded of all science.

\subsection{Conclusion}

While CA's place with respect to pragmatics has sometimes been contested, we have argued in this chapter that detailed transcription and collectionsbased analysis can contribute to leveraging open important areas of interest in sociopragmatics.

One important insight from CA is that underlying order in the ways in which sociopragmatic phenomena are interactionally accomplished can be found through detailed case-by-case analysis. While work in sociopragmatics often favours distributional analyses that investigate correlations between particular linguistic formats and sociopragmatic variables, CA offers a methodological alternative in its focus on the analysis of collections of individual cases. Analysing the idiosyncratic details of individual cases may seem to be moving us a long way from achieving the kind of empirical bite that is the aim of all scientific endeavour. However, as Jefferson (2002: 1377) argues, when "one begins to work with the materials on a case-by-case basis - where one might think that the further into the details one gets the murkier things become ... in fact the manifest order intensifies". A second key insight from CA is the importance of paying attention to sequential context as part of the broader attention to context in sociopragmatics. While in pragmatics there is considerable emphasis placed on the intentions of speakers in analysing what is meant, in CA "the focus shifts from speakers' intentions - the implication(s) that a speaker may (putatively) have intended in uttering a sentence - to the implications that recipients find in or attribute to a speaker's utterance in an empirical - i.e. sequential - context" (Drew 2018b: 244). A third overarching insight from CA for sociopragmatics is the importance of making discoveries through examining data in a bottom-up fashion in the first instance, not by assuming the necessary relevance of politeness, identity or other sociopragmatic touchstones in a particular situated context. The relevance of such issues emerges from the data and is discovered in it.

Looking forward, then, how might CA continue to productively inform sociopragmatics? Over the past decade, it can be seen that CA and sociopragmatics have been simultaneously converging and diverging as disciplines. On the one hand, the two fields are converging in calls to draw from a more diverse range of methods. The methodological distinctions that distinguish CA from pragmatics are arguably being challenged, as there are increasing attempts to bring other methods into CA. On the other hand, CA is increasingly moving towards multimodal analyses of 
interaction that do not privilege language in that analysis (Mondada 2019), thus moving away from the central focus placed on language use in pragmatics. We would suggest that the middle ground mediating between CA and sociopragmatics is increasingly likely to lie in the growth of interactional linguistics (Couper-Kuhlen and Selting 2018), and the push for increased methodological eclecticism within CA itself (Kendrick 2017). While they will no doubt continue to remain distinct endeavours, this does not mean to say, as Schegloff (2010) has previously argued, that a mutually beneficial fellowship between them cannot be cultivated.

\section{Appendix: Key CA Transcription Conventions}

\begin{tabular}{|l|l|}
\hline[] & overlapping speech \\
\hline$(0.5)$ & gap (in tenths of a second) \\
\hline$()$. & micropause \\
\hline$\cdot$ & falling or final intonation \\
\hline, & 'continuing' intonation \\
\hline$=$ & latched utterances \\
\hline$?$ & rising intonation \\
\hline$\downarrow \uparrow$ & sharply falling/rising intonation \\
\hline underlining & contrastive stress or emphasis \\
\hline$:$ & elongation of vowel or consonant sound \\
\hline- & word cut-off \\
\hline CAPS & markedly louder \\
\hline$\circ 0$ & markedly soft \\
\hline .hhh & in-breathing \\
\hline (hh) & interpolated laughter/aspiration \\
\hline$><$ & talk is compressed or rushed \\
\hline$<>$ & talk is markedly slowed or drawn out \\
\hline
\end{tabular}

\section{References}

Arundale, R. B. (2010). Constituting face in conversation: Face, facework, and interactional achievement. Journal of Pragmatics, 42, 2078-2105.

Arundale, R. B. (2020). Communicating and Relating: Constituting Face in Everyday Interacting. Oxford: Oxford University Press.

Austin, J. L. ([1962] 1975). How to Do Things with Words. 2nd ed. Edited by J. O. Urmson and M. Sbisà. Cambridge, MA: Harvard University Press. 
Bayraktaroğlu, A. and Sifianou, M. (2012). The iron fist in a velvet glove: How politeness can contribute to impoliteness. Journal of Politeness Research, 8(2), 143-60.

Brown, P. and Levinson, S. (1987). Politeness: Some Universals in Language Usage. Cambridge: Cambridge University Press.

Clayman, S. and Heritage, J. (2014). Benefactors and beneficiaries: Benefactive status and stance in the management of offers and requests. In E. Couper-Kuhlen and P. Drew, eds., Requesting in Interaction. Amsterdam: John Benjamins, pp. 55-86.

Clift, R. (2001). Meaning in interaction: The case of actually. Language, 77(2), 245-91.

Clift, R. (2005). Discovering order. Lingua, 115, 1641-65.

Clift, R. (2012). Identifying action: Laughter in non-humorous reported speech. Journal of Pragmatics, 44, 1303-12.

Clift, R. (2014). Conversation analysis. In K. P. Schneider and A. Barron, eds., Pragmatics of Discourse. Berlin: Mouton de Gruyter, pp. 97-124.

Clift, R. (2016). Conversation Analysis. Cambridge: Cambridge University Press.

Clift, R. and Raymond, C. (2018). Actions in practice: On details in collections. Discourse Studies, 20(1), 90-119.

Cook, H. M. (2006). Japanese politeness as an interactional achievement: Academic consultation sessions in Japanese universities. Multilingua, 25, 269-91.

Couper-Kuhlen, E. and Selting, M. (2018). Interactional Linguistics. Cambridge: Cambridge University Press.

Curl, T. (2006). Offers of assistance: Constraints on syntactic design. Journal of Pragmatics, 38, 1257-80.

Curl, T. and Drew, P. (2008). Contingency and action: A comparison of two forms of requesting. Research on Language and Social Interaction, 41, 129-53.

Drew, P. (2018a). The interface between pragmatics and conversation analysis. In C. Ilie and N. Norrick, eds., Pragmatics and Its Interfaces. Amsterdam: John Benjamins, pp. 59-83.

Drew, P. (2018b). Inferences and indirectness in interaction. Open Linguistics, $4,241-59$.

Drew, P. and Holt, E. (1998). Figures of speech: Figurative expressions and the management of topic transition in conversation. Language in Society, 27, 495-522.

Drew, P., Walker, T. and Ogden, R. (2013). Self-repair and action construction. In M. Hayashi, G. Raymond and J. Sidnell, eds., Conversational Repair and Human Understanding. Cambridge: Cambridge University Press, pp. 71-94.

Evans, N. and Levinson, S. (2009). The myth of language universals: Language diversity and its importance for cognitive science. Behavioral and Brain Sciences, 32, 429-92.

Ferenčik, M. (2007). Exercising politeness: Membership categorisation in a radio phone-in programme. Pragmatics, 17(3), 351-70. 
Flint, N., Haugh, M. and Merrison, A. J. (2019). Modulating troubles affiliating in initial interactions. Pragmatics, 29(3), 384-409.

Floyd, S., Rossi, G. and Enfield, N. J. (in press). Getting Others to Do Things: A Pragmatic Typology of Recruitments. Berlin: Language Science Press.

Garfinkel, H. and Sacks, H. (1970). On formal structures of practical actions. In J. C. McKinney and E. A. Tiraykian, eds., Theoretical Sociology. New York: Appleton Century Crofts, pp. 338-66.

Goffman, E. (1961). Encounters: Two Studies in the Sociology of Interaction. Indianapolis, IN: Bobbs-Merrill.

Haugh, M. (2013). Im/politeness, social practice and the participation order. Journal of Pragmatics, 58, 52-72.

Haugh, M. (2015). Im/politeness Implicatures. Berlin: Mouton de Gruyter.

Haugh, M. (2017). Prompting offers of assistance in interaction. Pragmatics and Society, 8, 183-207.

Haugh, M. (forthcoming). Action ascription, accountability and inference. In A. Deppermann and M. Haugh, eds., Action Ascription. Cambridge: Cambridge University Press.

Hepburn, A. and Bolden, G. (2017). Transcribing for Social Research. Thousand Oaks, CA: Sage.

Heritage, J. (1984). A change of state token and aspects of its sequential placement. In J. M. Atkinson and J. Heritage, eds., Structures of Social Action. Cambridge: Cambridge University Press, pp. 299-345.

Heritage, J. (1998). Oh-prefaced responses to inquiry. Language in Society, 27, 291-334.

Heritage, J. and Raymond, G. (2005). The terms of agreement: ndexing epistemic authority and subordination in talk-in-interaction. Social Psychology Quarterly, 68, 15-38.

Hutchby, I. (2008). Participants' orientations to interruptions, rudeness and other impolite acts in talk-in-interaction. Journal of Politeness Research, 4(2), 221-41.

Jefferson, G. (1979). A technique for inviting laughter and its subsequent acceptance-declination. In G. Psathas, ed., Everyday Language: Studies in Ethnomethodology. New York: Irvington, pp. 79-95.

Jefferson, G. (1984). On the organization of laughter in talk about troubles. In J. M. Atkinson and J. Heritage, eds., Structures of Social Action. Cambridge: Cambridge University Press, pp. 346-69.

Jefferson, G. (1985). An exercise in the transcription and analysis of laughter. In T. van Dijk, ed., Handbook of Discourse Analysis, Vol. 3, Discourse and Dialogue. London: Academic Press, pp. 25-34.

Jefferson, G. (2002). Is 'no' an acknowledgement token? Comparing American and British uses of $(+) /(-)$ tokens. Journal of Pragmatics, 34, 1345-83.

Jefferson, G. (2004a). Glossary of transcript symbols with an introduction. In G. Lerner, ed., Conversation Analysis: Studies from the First Generation. Amsterdam: John Benjamins, pp. 13-23. 
Jefferson, G. (2004b). A note on laughter in 'male-female' interaction. Discourse Studies, 6, 117-33.

Jefferson, G., Sacks, H. and Schegloff, E. (1987). Notes on laughter in the pursuit of intimacy. In G. Button and J. R. E. Lee, eds., Talk and Social Organisation. Clevedon, UK: Multilingual Matters, pp. 152-205.

Kendrick, K. (2017). Using conversation analysis in the lab. Research on Language and Social Interaction, 50, 1-11.

Kendrick, K. and Drew, P. (2014). The putative preference for offers over requests. In P. Drew and E. Couper-Kuhlen, eds., Requesting in Social Interaction. Amsterdam: John Benjamins, pp. 87-113.

Kendrick, K., Brown, P., Dingemanse, M., Floyd, S., Gipper, S., Hayano, K., Hoey, E., Hoymann, G., Manrique, G., Rossi, G. and Levinson, S. C. (in press). Sequence organization: A universal infrastructure for social action. Journal of Pragmatics.

Kendrick, K. and Drew, P. (2016). Recruitments: Offers, requests, and the organization of assistance in interaction. Research on Language and Social Interaction, 49, 1-19.

Kitzinger, C. (2005). Speaking as a heterosexual: (How) does sexuality matter for talk-in-interaction? Research on Language and Social Interaction, 38(3), 221-65.

Kitzinger, C. and Mandelbaum, J. (2013) Word selection and social identities in talk-in-interaction. Communication Monographs, 80(2), 176-98.

Krzeszowski, T. (1990). Contrasting Languages: The Scope of Contrastive Linguistics. Berlin: Mouton de Gruyter

Levinson, S. C. (2000). Presumptive Meanings: The Theory of Generalized Conversational Implicature. Cambridge, MA: MIT Press.

Merrison, A. J. (2011). Doing aphasia - 'are you with me?': Analysing facework around issues of (non-)competence. In LPRG, ed., Discursive Approaches to Politeness. Berlin: Mouton de Gruyter, pp. 221-44.

Mondada, L. (2019). Contemporary issues in conversation analysis: Embodiment and materiality, multimodality and multisensoriality in social interaction. Journal of Pragmatics, 145, 47-62.

Piirainen-Marsh, A. (2005). Managing adversarial questioning in broadcast interviews. Journal of Politeness Research, 1(1), 193-217.

Pillet-Shore, D. (in press). When to make the sensory social: Registering in face-to-face openings. Symbolic Interaction.

Pomerantz, A. (1984). Agreeing and disagreeing with assessments: Some features of preferred/dispreferred turn shapes. In J. M. Atkinson and J. Heritage, eds., Structures of Social Action: Studies in Conversation Analysis. Cambridge: Cambridge University Press, pp. 57-101.

Pomerantz, A. (2017). Inferring the purpose of a prior query and responding accordingly. In G. Raymond, G. Lerner and J. Heritage, eds., Enabling Human Conduct. Amsterdam: John Benjamins, pp. 61-77.

Pomerantz, A. and Heritage, J. (2013). Preference. In J. Sidnell and T. Stivers, eds., Handbook of Conversation Analysis. Malden, MA: Wiley-Blackwell, pp. 210-28. 
Pomerantz, A. and Mandelbaum, J. (2005). Conversation analytic approaches to the relevance and uses of relationship categories in interaction. In K. Fitch and R. Sanders, eds., Handbook of Language and Social Interaction. Mahwah, NJ: Erlbaum, pp. 149-71.

Raymond, G. (2003). Grammar and social organization: Yes/no interrogatives and the structure of responding. American Sociological Review, 68, 939-67.

Raymond, G. and Heritage, J. (2006). The epistemics of social relations: Owning grandchildren. Language in Society, 35, 677-705.

Robinson, J. (2016). Accountability in social interaction. In J. Robinson, ed., Accountability in Social Interaction. Oxford: Oxford University Press, pp. 1-44.

Sacks, H. (1972). An initial investigation of the usability of conversational data for doing sociology. In D. Sudnow, ed., Studies in Social Interaction. New York: The Free Press, pp. 31-75.

Sacks, H. (1984). Notes on methodology. In J. M. Atkinson and J. Heritage, eds., Structures of Social Action. Cambridge: Cambridge University Press, pp. 21-27.

Sacks, H. (1992a). Lectures on Conversation. Vol. 1. Oxford: Blackwell.

Sacks, H. (1992b). Lectures on Conversation. Vol. 2. Oxford: Blackwell.

Sacks, H. and Schegloff, E. (1979). Two preferences in the organization of reference to persons in conversation and their interaction. In G. Psathas, ed., Everyday Language: Studies in Ethnomethodology. New York: Irvington, pp. 15-21.

Schegloff, E. (1968). Sequencing in conversational openings. American Anthropologist, 70(6), 1075-95.

Schegloff, E. (1993). Reflections on quantification in the study of conversation. Research on Language and Social Interaction, 26, 99-128.

Schegloff, E. (1996). Confirming allusions: Toward an empirical account of action. American Journal of Sociology, 102, 161-216.

Schegloff, E. (1997). Practices and actions: Boundary cases of otherinititated repair. Discourse Processes, 23, 499-545.

Schegloff, E. (2000). On granularity. Annual Review of Sociology, 26, 715-20.

Schegloff, E. (2007). Sequence Organization in Interaction. Cambridge: Cambridge University Press.

Schegloff, E. (2010). Commentary on Stivers and Rossano: 'Mobilising response'. Research on Language and Social Interaction, 43, 38-48.

Schegloff, E. (2017). Conversation analysis. In Y. Huang, ed., The Oxford Handbook of Pragmatics. Oxford: Oxford University Press, pp. 435-49.

Schegloff, E., Jefferson, G. and Sacks, H. (1977). The preference for self-correction in the organisation of repair in conversation. Language, 53(2), 361-82.

Schegloff, E. and Lerner, G. (2009). Beginning to respond: Well-preface responses to wh-questions. Research on Language and Social Interaction, 42, 91-115.

Schenkein, J. (ed.). (1978). Studies in the Organization of Conversational Interaction. New York: Academic Press.

Searle, J. R. (1969). Speech Acts: An Essay in the Philosophy of Language. Cambridge: Cambridge University Press. 